\title{
QUALITY OF LIFE IN PATIENTS WITH DEPRESSIVE DISORDERS
}

\author{
Oleksandr Belov \\ Ph.D., Associate Professor, National Pirogov Memorial Medical University, Ukraine \\ e-mail: oleksbelov@gmail.com,orcid.org/0000-0002-0156-0777
}

\section{Summary}

The aim of this paper is to study the features of quality of life in patients with depressive disorders, taking into account age and gender. Clinically examined 107 men and 138 women with depressive disorders (ICD-10 codes F31.3, F31.4, F32.0, F32.1, F32.2, F33.0, F33.1, F33.2) using Multicultural Quality of Life Index. Depressive disorders are accompanied by a significant deterioration in the quality of life of patients, principally in psychological (emotional) well-being. In general, quality of life indicators decrease as patients age; women showed lower self-reported quality of life in most areas, these differences were statistically significant in the younger and middle age groups. The assessments of the quality of life of patients by the specialist turned out to be significantly $(p<0.001)$ higher than the self-assessments of patients for all areas of the quality of life, especially in women. The closest self-esteem and quality of life assessment by a specialist were for psychological (emotional) well-being, and the largest differences were found for interpersonal functioning, social-emotional support, community and services support, personal fulfillment, spiritual fulfillment, and overall quality of life. While subjectively patients note the greatest decrease in the quality of life between the ages of 30 and 44 , while according to a specialist's assessment, the quality of life decreases most significantly at the age of over 45 , especially in women.

Keywords: depression, psychological, emotional well-being, age, gender.

DOI: https://doi.org/10.23856/4429

\section{Introduction}

Depressive disorders are one of the main problems of modern psychiatric science and practice. Their lifetime prevalence is estimated at 5-17\%, and according to the WHO, major depressive disorder is the third largest cause of disease burden in the world, and, according to experts, by 2030 will come out on top (WHO, 2015; Malhi G.S., Mann J.J., 2018; Murray C.J., 2018).

Depression is a disease that is accompanied by severe socio-psychological maladaptation and significant deterioration of psychosocial functioning (Hammer-Helmich L. et al., 2018; Saragoussi D. et al, 2018). In depressive disorders there are pronounced disorders of microsocial functioning not only of the patients themselves, but also of their immediate environment, in particular, the deformation of homeostasis of the family system (Pshuk N. et al., 2018).

An important role in the final result of treatment is played by quality of life and psychosocial readaptation of patients, which affects the quality and duration of remission (Kraus C. et al., 2019). Restoration of full social functioning and quality of life of patients is also an important factor in reducing the therapeutic resistance of affective disorders (Markova M. et al., 2017).

Depressive disorders are also accompanied by a significant deterioration in the quality of life of patients. The quality of life is considered as one of the key indicators of the 
biopsychosocial functioning of an individual, as well as an important indicator of the effectiveness of treatment and rehabilitation for mental disorders (Dhungana S. et al., 2021).

Continued research on the quality of life of depressed patients is important in the context of the pathomorphosis of depressive disorders (Cleare A. et al., 2015). It is obvious that a change in the clinical course of depressive disorders affects the quality of life of patients and the prospects for restoring their social functioning, and these features need to be studied.

All this determines the relevance of modern studies of the quality of life of patients with depression and the need for a detailed study of the characteristics of the quality of life in different areas, taking into account age and gender characteristics.

\section{The aim of the study}

The aim is to study the features of quality of life in patients with depressive disorders, taking into account age and gender.

\section{Materials and methods}

With the observance of the principles of biomedical ethics, we have clinically examined 107 men and 138 women who applied for medical care at Vinnytsya Regional Psycho-Neurological Hospital and Department of Medical Psychology and Psychiatry National Pirogov Memorial Medical University from 2015 to 2019. The nosological structure of the contingent was as follows ICD-10 codes: F31.3, F31.4, F32.0, F32.1, F32.2, F33.0, F33.1, F33.2. The average age of the men was $34.2 \pm 11.1$ years, and $33.2 \pm 11.4$ years for women $(\mathrm{p}=0.422)$, the average duration of depression was $5.7 \pm 5.8$ years for men, and $4.5 \pm 5.4$ years for women $(p=0.064) .3$ subgroups were allocated in group of men and women depending on the age of patients at the time of the study: up to 30 years (M1 and W1, respectively), from 33 to 44 years (M2 and W2 groups, respectively), 45 years and older (M3 and W3 groups, respectively). The study was conducted using Multicultural Quality of Life Index (MQLI) (Mezzich J. et al., 2011). Statistical analysis of differences between groups was carried out using non-parametric Mann-Whitney test.

\section{Results}

In general, patients with depression (both men and women) have low levels of quality of life according to self-reported data (Tables 1 and 2). Patients rate their quality of life the lowest in psychological (emotional) well-being, where the average indicators are less than 3 points out of 10 in the younger age groups (M1 and W1), and further decrease to 1.7-2.0 points in the middle age groups. groups (M2 and W2) up to 1.4-1.6 in older groups (M3 and W3). Low self-esteem scores (within 2.0-4.0 points in M1 and W1 groups, within 1.7-3.0 points in M2 and W2 groups, and within 1.4-2.8 points in M3 groups and W3) were also identified for physical well-being, occupational functioning, personal fulfillment and overall quality of life, and in women - for interpersonal functioning. The highest self-esteem indices were found in the areas of community and services support, social-emotional support and spiritual fulfillment (from 4.6-6.8 points in the M1 and W1 groups to 2.5-5.6 points in the M3 and W3 groups). 
Table 1

Self-reported characteristics of quality of life in men with depressive disorders

\begin{tabular}{|l|c|c|c|c|c|c|}
\hline \multirow{2}{*}{\multicolumn{1}{|c|}{ Item }} & \multicolumn{3}{|c|}{ Value, points } & \multicolumn{3}{c|}{ p } \\
\cline { 2 - 7 } & $\mathbf{M 1}$ & $\mathbf{M 2}$ & $\mathbf{M 3}$ & $\begin{array}{c}\text { M1 vs } \\
\text { M2 }\end{array}$ & $\begin{array}{c}\text { M1 vs } \\
\text { M3 }\end{array}$ & $\begin{array}{c}\text { M2 vs } \\
\text { M3 }\end{array}$ \\
\hline Physical well-being & $3,68 \pm 1,36$ & $2,80 \pm 1,15$ & $1,65 \pm 0,88$ & 0,002 & 0,000 & 0,000 \\
\hline $\begin{array}{l}\text { Psychological (emotional) } \\
\text { well-being }\end{array}$ & $2,82 \pm 1,04$ & $2,00 \pm 0,67$ & $1,61 \pm 0,58$ & 0,000 & 0,000 & 0,022 \\
\hline $\begin{array}{l}\text { Self-care and independent } \\
\text { functioning }\end{array}$ & $4,34 \pm 0,78$ & $2,96 \pm 1,59$ & $2,35 \pm 0,78$ & 0,000 & 0,000 & 0,261 \\
\hline Occupational functioning & $3,00 \pm 0,96$ & $2,22 \pm 0,96$ & $1,30 \pm 0,47$ & 0,000 & 0,000 & 0,000 \\
\hline Interpersonal functioning & $4,63 \pm 1,42$ & $4,09 \pm 1,62$ & $2,83 \pm 0,94$ & 0,125 & 0,000 & 0,002 \\
\hline Social-emotional support & $5,79 \pm 1,77$ & $3,17 \pm 1,30$ & $2,70 \pm 1,22$ & 0,000 & 0,000 & 0,132 \\
\hline Community and services support & $6,76 \pm 1,17$ & $6,43 \pm 1,66$ & $5,52 \pm 1,38$ & 0,402 & 0,001 & 0,020 \\
\hline Personal fulfillment & $3,29 \pm 1,29$ & $2,89 \pm 1,34$ & $2,04 \pm 1,11$ & 0,228 & 0,001 & 0,013 \\
\hline Spiritual fulfillment & $5,00 \pm 1,38$ & $4,63 \pm 1,85$ & $3,78 \pm 1,81$ & 0,418 & 0,009 & 0,081 \\
\hline Overall quality of life & $3,37 \pm 1,53$ & $1,78 \pm 1,46$ & $1,43 \pm 0,66$ & 0,000 & 0,000 & 0,831 \\
\hline Total score & $4,27 \pm 0,82$ & $3,30 \pm 0,96$ & $2,52 \pm 0,68$ & 0,000 & 0,000 & 0,001 \\
\hline
\end{tabular}

The general trend is the deterioration quality of life indicators decrease as patients age. In men, more significant differences between the younger and middle age groups were found for physical well-being, psychological (emotional) well-being, self-care and independent functioning, occupational functioning, social-emotional support, overall quality of life and total score of quality of life. Between the middle and older age groups, more significant differences were found for interpersonal functioning, community and services support, and personal fulfillment. In women, more significant differences between the younger and middle age groups were found for psychological (emotional) well-being, social-emotional support, community and services support, personal fulfillment, spiritual fulfillment, overall quality of life, and total score, and between middle and senior age groups - for physical well-being, occupational functioning and interpersonal functioning.

Table 2

Self-reported characteristics of quality of life in women with depressive disorders

\begin{tabular}{|l|c|c|c|c|c|c|}
\hline \multicolumn{1}{|c|}{ Item } & W1 & $\mathbf{W}$ & $\mathbf{W 3}$ & $\begin{array}{c}\text { W1 vs } \\
\text { W2 }\end{array}$ & $\begin{array}{c}\text { W1 vs } \\
\text { W3 }\end{array}$ & $\begin{array}{c}\text { W2 vs } \\
\text { W3 }\end{array}$ \\
\hline Physical well-being & $2,90 \pm 1,75$ & $2,25 \pm 1,19$ & $1,50 \pm 0,75$ & 0,058 & 0,000 & 0,004 \\
\hline $\begin{array}{l}\text { Psychological (emotional) } \\
\text { well-being }\end{array}$ & $2,25 \pm 1,09$ & $1,68 \pm 0,64$ & $1,38 \pm 0,55$ & 0,008 & 0,000 & 0,029 \\
\hline $\begin{array}{l}\text { Self-care and independent } \\
\text { functioning }\end{array}$ & $3,39 \pm 1,91$ & $2,47 \pm 1,22$ & $2,18 \pm 1,11$ & 0,019 & 0,006 & 0,277 \\
\hline Occupational functioning & $2,49 \pm 1,43$ & $1,92 \pm 1,09$ & $1,41 \pm 0,66$ & 0,054 & 0,000 & 0,026 \\
\hline Interpersonal functioning & $3,88 \pm 1,70$ & $3,38 \pm 1,76$ & $2,44 \pm 1,19$ & 0,143 & 0,000 & 0,018 \\
\hline Social-emotional support & $4,67 \pm 2,51$ & $2,55 \pm 1,32$ & $2,50 \pm 1,21$ & 0,000 & 0,000 & 0,968 \\
\hline Community and services support & $7,12 \pm 1,56$ & $6,08 \pm 1,74$ & $5,59 \pm 2,24$ & 0,002 & 0,002 & 0,417 \\
\hline Personal fulfillment & $3,45 \pm 1,21$ & $2,72 \pm 1,47$ & $1,88 \pm 0,81$ & 0,003 & 0,000 & 0,008 \\
\hline Spiritual fulfillment & $5,24 \pm 1,58$ & $4,43 \pm 1,93$ & $4,15 \pm 1,83$ & 0,036 & 0,004 & 0,468 \\
\hline Overall quality of life & $2,35 \pm 1,09$ & $1,77 \pm 1,07$ & $1,41 \pm 0,61$ & 0,002 & 0,000 & 0,182 \\
\hline Total score & $3,77 \pm 1,22$ & $2,92 \pm 0,97$ & $2,44 \pm 0,84$ & 0,001 & 0,000 & 0,039 \\
\hline
\end{tabular}


In general, women showed lower self-reported quality of life in most areas. However, these differences were statistically significant only in the younger and middle age groups. When comparing the M1 and W1 groups, significant differences were found for physical well-being $(p=0.042)$, psychological (emotional) well-being $(p=0.020)$, self-care and independent functioning $(p=0.026)$, interpersonal functioning $(p=0.035)$, social-emotional support $(p=0.027)$, and overall quality of life $(\mathrm{p}=0.001)$. When comparing the M2 and W2 groups, significant differences were found for physical well-being $(\mathrm{p}=0.024)$, psychological (emotional) well-being $(p=0.018)$, interpersonal functioning $(p=0.040)$, social-emotional support $(p=0.020)$. Between the M3 and W3 groups, the differences in quality of life indicators in all spheres are statistically insignificant $(\mathrm{p}>0.05)$.

It is important to understand the peculiarities of the subjective perception of patients with depression of their social functioning and quality of life by comparing the data of self-assessment of the quality of life and the assessment of these same areas by a specialist psychiatrist. We carried out such a comparison, which allowed us to identify interesting patterns (table 3 and 4).

In general, the assessments of the quality of life of patients by the specialist turned out to be significantly $(\mathrm{p}<0.001)$ higher than the self-assessments of patients for all areas of the quality of life. This difference is especially pronounced in women. The closest self-esteem and quality of life assessment by a specialist were for psychological (emotional) well-being, and the largest differences were found for interpersonal functioning, social-emotional support, community and services support, personal fulfillment, spiritual fulfillment, and overall quality of life.

Table 3

Quality of life characteristics in men with depressive disorders as assessed by a specialist

\begin{tabular}{|l|c|c|c|c|c|c|}
\hline \multirow{2}{*}{\multicolumn{1}{|c|}{ Item }} & \multicolumn{3}{|c|}{ Value, points } & \multicolumn{3}{c|}{ p } \\
\cline { 2 - 7 } & $\mathbf{M 1}$ & $\mathbf{M 2}$ & $\mathbf{M 3}$ & $\begin{array}{c}\text { M1 vs } \\
\text { M2 }\end{array}$ & $\begin{array}{c}\text { M1 vs } \\
\text { M3 }\end{array}$ & $\begin{array}{c}\text { M2 vs } \\
\text { M3 }\end{array}$ \\
\hline Physical well-being & $5,39 \pm 2,05$ & $3,98 \pm 2,48$ & $3,13 \pm 2,30$ & 0,008 & 0,000 & 0,156 \\
\hline $\begin{array}{l}\text { Psychological (emotional) } \\
\text { well-being }\end{array}$ & $3,13 \pm 1,28$ & $2,15 \pm 1,23$ & $1,78 \pm 1,17$ & 0,001 & 0,000 & 0,150 \\
\hline $\begin{array}{l}\text { Self-care and independent } \\
\text { functioning }\end{array}$ & $5,26 \pm 1,48$ & $3,93 \pm 1,94$ & $2,74 \pm 1,84$ & 0,002 & 0,000 & 0,025 \\
\hline Occupational functioning & $3,95 \pm 1,16$ & $3,07 \pm 1,60$ & $2,39 \pm 1,50$ & 0,003 & 0,000 & 0,057 \\
\hline Interpersonal functioning & $6,21 \pm 0,96$ & $5,67 \pm 1,19$ & $4,39 \pm 1,50$ & 0,016 & 0,000 & 0,001 \\
\hline Social-emotional support & $7,84 \pm 1,22$ & $6,65 \pm 1,49$ & $5,70 \pm 1,89$ & 0,000 & 0,000 & 0,025 \\
\hline Community and services support & $9,55 \pm 1,33$ & $8,48 \pm 2,48$ & $7,00 \pm 3,66$ & 0,027 & 0,003 & 0,129 \\
\hline Personal fulfillment & $6,11 \pm 0,80$ & $5,20 \pm 1,19$ & $4,30 \pm 1,61$ & 0,000 & 0,000 & 0,027 \\
\hline Spiritual fulfillment & $7,50 \pm 1,27$ & $6,93 \pm 1,20$ & $5,57 \pm 0,99$ & 0,043 & 0,000 & 0,000 \\
\hline Overall quality of life & $4,79 \pm 0,66$ & $3,98 \pm 0,93$ & $3,30 \pm 1,43$ & 0,000 & 0,000 & 0,072 \\
\hline Total score & $5,97 \pm 0,92$ & $5,00 \pm 1,32$ & $4,03 \pm 1,52$ & 0,001 & 0,000 & 0,008 \\
\hline
\end{tabular}

The general trend towards a deterioration in the quality of life with the age of patients persists even when evaluated by a specialist. In men, the most pronounced deterioration in performance between groups M1 and M2 was revealed for physical well-being, psychological (emotional) well-being, self-care and independent functioning, occupational functioning, social-emotional support, community and services support, personal fulfillment, overall quality 
of life and for total score of quality of life. A more pronounced deterioration in performance between groups M2 and M3 was revealed for interpersonal functioning, and spiritual fulfillment. In women, all indicators of quality of life deteriorate more significantly when comparing groups W2 and W3 than when comparing groups W1 and W2.

Table 4

Quality of life characteristics in women with depressive disorders as assessed by a specialist

\begin{tabular}{|l|c|c|c|c|c|c|}
\hline \multirow{2}{*}{\multicolumn{1}{c|}{ Item }} & \multicolumn{3}{|c|}{ Value, points } & \multicolumn{3}{c|}{ p } \\
\cline { 2 - 7 } & $\mathbf{W 1}$ & $\mathbf{W 2}$ & $\mathbf{W 3}$ & $\begin{array}{c}\text { W1 vs } \\
\text { W2 }\end{array}$ & $\begin{array}{c}\text { W1 vs } \\
\text { W3 }\end{array}$ & $\begin{array}{c}\text { W2 vs } \\
\text { W3 }\end{array}$ \\
\hline Physical well-being & $6,04 \pm 2,12$ & $4,77 \pm 2,50$ & $2,82 \pm 1,88$ & 0,008 & 0,000 & 0,000 \\
\hline $\begin{array}{l}\text { Psychological (emotional) } \\
\text { well-being }\end{array}$ & $3,43 \pm 1,30$ & $2,72 \pm 1,41$ & $1,71 \pm 1,00$ & 0,009 & 0,000 & 0,001 \\
\hline $\begin{array}{l}\text { Self-care and independent } \\
\text { functioning }\end{array}$ & $5,45 \pm 1,49$ & $4,96 \pm 2,14$ & $2,76 \pm 1,78$ & 0,285 & 0,000 & 0,000 \\
\hline Occupational functioning & $4,27 \pm 1,33$ & $3,64 \pm 1,35$ & $2,44 \pm 1,44$ & 0,018 & 0,000 & 0,000 \\
\hline Interpersonal functioning & $6,41 \pm 1,17$ & $5,89 \pm 1,25$ & $4,74 \pm 1,38$ & 0,033 & 0,000 & 0,000 \\
\hline Social-emotional support & $7,86 \pm 1,15$ & $7,34 \pm 1,60$ & $5,74 \pm 1,78$ & 0,173 & 0,000 & 0,000 \\
\hline Community and services support & $9,35 \pm 1,40$ & $9,15 \pm 2,08$ & $7,56 \pm 3,22$ & 1,000 & 0,011 & 0,020 \\
\hline Personal fulfillment & $6,37 \pm 1,00$ & $5,77 \pm 1,01$ & $4,15 \pm 1,33$ & 0,006 & 0,000 & 0,000 \\
\hline Spiritual fulfillment & $8,14 \pm 1,34$ & $7,32 \pm 1,34$ & $6,00 \pm 1,23$ & 0,005 & 0,000 & 0,000 \\
\hline Overall quality of life & $5,00 \pm 0,80$ & $4,62 \pm 0,97$ & $3,24 \pm 1,30$ & 0,053 & 0,000 & 0,000 \\
\hline Total score & $6,23 \pm 1,08$ & $5,62 \pm 1,25$ & $4,11 \pm 1,36$ & 0,011 & 0,000 & 0,000 \\
\hline
\end{tabular}

When comparing quality of life indicators in men and women according to the assessment by a specialist, statistically significant differences were revealed mainly in the middle age group (M2 vs W2): for psychological (emotional) well-being $(\mathrm{p}=0.042)$, self-care and independent functioning $(\mathrm{p}=0.019)$, occupational functioning $(\mathrm{p}=0.026)$, social-emotional support $(p=0.024)$, personal fulfillment $(p=0.013)$, overall quality of life $(p=0.001)$, and total score of quality of life $(\mathrm{p}=0.028)$. In the younger age group (M1 vs W1), significant differences were found for spiritual fulfillment only $(\mathrm{p}=0.034)$, and in the older age group (M3 vs W3), the differences between all indicators of quality of life in men and women are not statistically significant $(\mathrm{p}>0,05)$.

\section{Discussion}

The data obtained in our study coincide with the data of many earlier studies that established low levels of quality of life in patients with depressive disorders. Low mood, pessimism, anhedonia, asthenia, which are the key symptoms of depression, cause low self-esteem in those areas of quality of life that reflect the perception of one's physical and psychological state. It should be noted that, despite low self-esteem, the lowest indicators of quality of life in the emotional sphere are an adequate reflection of affective pathology, especially in cases of severe depression. It is natural that the indicators of self-assessment of the quality of life in this area, according to self-assessment data, are the closest to those of a specialist's assessment. At the same time, indicators in the field of physical health in self-assessment by patients were clearly underestimated under the influence of depressive perception, while indicators according to the 
assessment by a specialist were satisfactory. Depression reduces the level of social interaction of patients and worsens the quality of life in those areas that reflect the individual's social activity (interpersonal functioning, social-emotional support, community and services support, personal fulfillment, spiritual fulfillment), and this leads to low scores.

The gender differences in the quality of life of patients with depression identified in our study were consistent with the data of some earlier studies, which noted lower indicators of the quality of life in women. Women tend to be more attentive to their condition, including mental, and emotional problems are more difficult. It is important to note that according to the assessment of the quality of life by a specialist, women have higher indicators than men, while according to self-assessment, the ratio is the opposite. This is consistent with our data on the same population of patients about higher rates of depression in men compared with women. At the same time, it should be borne in mind that trends may differ in different age groups.

The general pattern of deterioration in the quality of life with age reflects the progression of the depressive process, as well as the general decline in mental and social functioning associated with aging. At the same time, subjectively, patients note a more significant decrease in the quality of life between the ages of 30 and 44, while according to a specialist's assessment, the greatest deterioration in the quality of life of patients with depression occurs at the age of over 45 , especially in women.

\section{Conclusions}

Depressive disorders are accompanied by a significant deterioration in the quality of life of patients.

The lowest indicators of quality of life were noted for psychological (emotional) well-being, low indicators were also found for physical well-being, occupational functioning, personal fulfillment and overall quality of life.

According to the data of a subjective assessment, the quality of life is lower in women, and according to the assessment by a specialist - in men.

The quality of life decreases with the age of patients, while subjectively patients note the greatest decrease in the quality of life between the ages of 30 and 44, while according to a specialist's assessment, the quality of life decreases most significantly at the age of over 45 , especially in women.

\section{References}

Global Burden of Disease Study C Global, regional, and national incidence, prevalence, and years lived with disability for 301 acute and chronic diseases and injuries in 188 countries, 1990-2013: a systematic analysis for the Global Burden of Disease Study 2013. (2015). Lancet, 386, 743-800.

Cleare A., Pariante C.M., Young A.H. (2015). Evidence-based guidelines for treating depressive disorders with antidepressants: a revision of the 2008 British Association for Psychopharmacology guidelines. Journal of Psychopharmacology, 29(5), 459-525.

Dhungana, S., Koirala, R., Ojha, S.P. et al. (2021). Quality of life and its association with psychiatric disorders in outpatients with trauma history in a tertiary hospital in Kathmandu, Nepal: a cross-sectional study. BMC Psychiatry, 21, 98. 
Hammer-Helmich L., Haro J.M., Jönsson B., Tanguy Melac A., Di Nicola S., Chollet J. et al. (2018). Functional impairment in patients with major depressive disorder: the 2-year PERFORM study. Neuropsychiatr Dis Treat, 14, 239-249.

Kraus C., Kadriu B., Lanzenberger R., Zarate C.A.., Kasper S. (2019). Prognosis and improved outcomes in major depression: a review. Translational Psychiatry, 9, 127.

Malhi G.S., Mann J.J. (2018). Depression. Lancet, 24(10161), 2299-2312.

Markova M., Rezunenko O., Kozhyna H. (2017). Contents and efficiency measures of psychoeducation in rehabilitation system of patients with bipolar affective disorder. Journal of Education, Health end Sport formerly Journal of Health Sciences, 7, 711-715.

Mezzich J., Cohen N.L., Ruiperez M.A., Banzato C. (2011). The Multicultural Quality of Life Index: presentation and validation. Journal of Evaluation in Clinical Practice, 17(2), 357-364. Murray C.J. (2018). Global, regional, and national incidence, prevalence, and years lived with disability for 354 diseases and injuries for 195 countries and territories, 1990-2017: a systematic analysis for the Global Burden of Disease Study 2017. Lancet, 392, 1789-1858.

Pshuk N.G., Stukan L.V., Kaminska A.O. (2018). Introducing system of psychotherapeutic intervention for family caregivers of patients with endogenous mental disorders. Wiadomosci Lekarskie, 71(5), 980-985.

Saragoussi D., Christensen M.C., Hammer-Helmich L., Rive B., Touya M., Haro J.M. (2018). Long-term follow-up on health-related quality of life in major depressive disorder: a 2-year European cohort study. Neuropsychiatr Dis Treat, 14, 1339-1350. 